\title{
TEORIJE SESTRINSTVA I NJIHOVE PRIMJENE U SESTRINSKOJ KLINIČKOJ PRAKSI
}

\author{
Boris Kovač \\ Fakultet zdravstvenih studija Sveučilišta u Mostaru, Bijeli Brijeg b.b., Bosna i Hercegovina \\ Rad je primljen 8.4.2018. Rad je recenziran 1.5.2018. Rad je prihvaćen 11.5.2018.
}

\section{SAŽETAK}

Teorija sestrinstva promišljeni je sustavni izraz preporuka vezanih za pitanja u disciplini zdravstvene skrbi. Predstavlja skup ideja, definicija, odnosa, očekivanja iprijedloga koji proizlaze iz modela skrbi ili proizlaze iz drugih disciplina, oblikujući specifične međusobne odnose među pojmovima u svrhu opisivanja, objašnjavanja, predviđanja i preporuka. Uloga sestrinske znanstvene teorije od velikog je značaja u procesu implementiranja stečenog znanja u sestrinskoj kliničkoj praksi. Teorije sestrinske prakse dovele su do prepoznavanja autentičnog identiteta sestrinstva, a zajedno s razvojem tehnologije i humanističkih znanosti oblikovale su i autentičnu sestrinsku praksu. Teorije se koriste u kliničkoj skrbničkoj praksi na dva različita načina. Prvi način je opća, orijentacijska uloga teorije koja služi za formuliranje stavova i obveza prema temeljnim obilježjima sestrinske prakse, čime utječe na način provođenja skrbi u svim kliničkim situacijama. Drugi način korištenja teorije je selektivna, situacijska uloga koja odgovara određenim specifičnim zahtjevima kliničke prakse. Na taj način sestrinska praksa u konačnici postaje znanje utemeljeno na integraciji ovih dvaju načina uporabe sestrinske teorije. Cilj rada: Ispitati teorije sestrinstva i načine njihove primjeneu sestrinskoj kliničkoj praksi.

Ključne riječi: teorija,sestrinstvo, primjena, klinička praksa

Osoba za razmjenu informacija:

Boris Kovač

E mail: boris.v.kovac@gmail.com

\section{UVOD}

Uloga sestrinske znanstvene teorije u kliničkoj medicinskoj praksi u središtu je interesa modernogsestrinstva. Teoriju kao vrstu znanja smatramo pokretačem poboljšanja kvalitete uvjeta ljudskog života te znanja koje usmjerava $\mathrm{k}$ boljim načinima rješavanja problema $s$ kojima se ljudi susreću. Sestrinska praksa kao humanistička djelatnost ima specifičan cilj poboljšanja ljudskog zdravlja i mora biti vođena sustavom sestrinskih znanja koja uključuju različite vrste teorija. U praktičnoj ulozi teorije se koriste u razumijevanju onoga što postoji ili ne postoji, što je dobro ili loše, ono što treba raditi ili ne raditi, što je korisno ili problematično u kliničkim situacijama. S druge strane, neke teorije se koriste za objašnjavanje onoga što postoji, dok neke igraju ulogu u oblikovanju i provođenju sestrinskih akcija u određenim kliničkim situacijama.

Zdravstvena se skrb ne može temeljiti na jednoj teoriji. Klinička praksa skrbi zahtijeva višestruke teorije na različitim razinama i u različite svrhe. Teorije nam ne mogu točno odrediti što raditi u kliničkim situacijama. One obavještavaju medicinske sestre o najboljim i najefektnijim postupcima koji se mogu obaviti u praksi unutar granica onoga što je poznato, ali istodobno to treba promatrati i u kontekstu jedinstvenih obilježja svake kliničke situacije. S obzirom na te pretpostavke, uloga teorije u sestrinskoj kliničkoj praksi razmatra se u perspektivama koje razgraničavaju prirodu skrbi, prirodu medicinskog znanja i koncepct prakse utemeljene na znanju. 


\section{POJAM SESTRINSKE ZNANOSTI}

Veliki je izazov jezgrovito definirati sestrinsku znanost bez uobičajene terminologije i bez korištenja izraza skrb. Skrb je osnova sestrinske profesije s različitim školama mišljenja koja tvore znanje o samoj disciplini. Određivanje pojma sestrinske znanosti još uvijek je zahtjevan zadatak zbog nepostojanja općeg konsenzusa među teoretičarima o samoj njenoj suštini (1).

Neki teoretičari sestrinsku znanost definiraju kroz naglašavanje određene vrste međuodnosa medicinskih sestara i njihovih klijenata, dok drugi pak koriste određene partikularne teorijske modele i filozofije ili određene specifične metodologije (2). Sestrinstvo je kao autonomna profesija novijega datuma, no njegova povijest svjedoči u prilog autentičnom zvanju, tj. karizmatskom pozivu sui generis za njegovanje bolesnika koji sačinjavasamu srž sestrinske prakse (3).

Definicija mora biti dovoljno široka kako bi obuhvatila sve aspekte znanosti vezane za skrb. Colley navodi da nije lako objasniti znanost koja se temelji na humanizmu a pri tom koristiti pojmove iz tradicionalnih prirodnih znanosti. To je zato što, za razliku od pojmova koji se opisuju u prirodnim znanostima, nije moguće opisivati čovjeka u bezuvjetnom kontekstu (4).

Mnogo autora i teoretičara obuhvaćalo je definicije onoga što im sestrinska znanost predstavlja. Daly i suradnici definiraju medicinsku znanost kao prepoznatljivo, diskretno tijelo znanja koje sadrži paradigme, okvire i teorije (5). Barrett navodi da sestrinska znanostpredstavlja klastere precizno odabranih uvjerenja i vrijednosti koje su oblikovane u različite teorijske strukture (6). Prema Kim provedba je njege domena znanja koja je prilagođena pojedincu ili skupinama i njihovim stvarnim ili potencijalnim zdravstvenim problemima, prema okolišu koji utječe na zdravlje ljudi i terapijskim intervencijama koje promiču zdravlje i utječu na posljedice bolesti (7).

Da bi se dobila jasna definicija koja obuhvaća svaki aspekt sestrinske znanosti te se definicije moraju kombinirati. Široka definicija profesije medicinskih sestara je razumijevanje ljudskog zdravlja, primjena tog znanja na iscjeljenje, s ciljem poboljšavanja mentalnog, tjelesnog i duhovnog zdravlje pojedinca (8). Sestrinstvo se može spram medicine i liječništva razmatrati kao zasebna znanstvena disciplina, zaokružena cjelina znanja, metoda, procedura i vještina, ali i neraskidivi dio cjelokupne medicinske znanosti uopće (9).

\section{TEORIJE SESTRINSKE ZNANOSTI}

Postoje konstantna razmatranja vezana za teoriju sestrinske znanosti i čini se da konačni zaključci još uvijek nisu usuglašeni. Nedostatak konsenzusa u profesionalnoj sestrinskoj literaturi često služi stvaranju nedoumica vezanih za definiranje teorije sestrinstva, unatoč činjenici na njenu dugotrajnost $\mathrm{i}$ svakodnevnu praksu kojoj svi svjedočimo. U smislu tradicionalne znanosti, teorija se može opisati kao skup utvrđenih izjava ili pravila koja moraju biti testirana (10).

Povijesno gledano, teorija sestrinske znanosti nastala je i razvijala se na temelju medicinske znanosti i njenih teorija. Međutim, pedesetih godina prošlog stoljeća nastao je konsenzus između vodećih teoretičara sestrinstva o potrebi validacije sestrinstva kao samostalne discipline testirane kroz praksu (11).

U toj činjenici leži i današnja brojna i ponekad potpuno različita razmišljanja o teoriji sestrinstva. Brojni teoretičari tvrde da je sestrinstvo postojalo mnogo prije nastanka koncepta teorije, da i danas i dalje postoji, neovisno što u mnogim sredinama još uvijek ne postoji zadovoljavajuća razina svijesti o teoriji sestrinske znanosti. Potrebno je osigurati temelje sestrinske prakse, omogućiti stvaranje novih znanja i jasno odrediti u kojem će se smjeru sestrinstvo razvijati dalje u budućnosti (12).

Unatoč kontradikcijama koje su zabilježene u poimanju sestrinstva kao tradicionalne znanosti, sestrinska teorija skrbi ostaje podložna tradicionaInim okvirima. Castledine smatra da svaki subjekt koji prolazi kroz rane stadije znanstvenog razvoja ili faze "pred-paradigme" mora biti podložan brojnim školama mišljenja i tek onda treba dosegnuti paradigmu kada se jedna teorija smatra apsolutnom (13). 
Ako je sestrinska teorija nastajala $\mathrm{u}$ istim uvjetima kao i tradicionalna znanost, onda bi bilo nemoguće provoditi praksu bez razumijevanja teorije sestrinstva i suštine same skrbi. Zbog raznolike prirode skrbi i nedostatka mjerljivosti njenog krajnjeg ishoda, teško je testirati ili provjeriti njen partikularni udio u konačnom ishodu, čime se teoriji sestrinske znanosti ne može prilaziti razmišljanjima koja su u opsegu tradicionalnih znanosti (14).

Teorija sestrinstva predstavlja dobro promišljeni sustavni izraz preporuka vezanih za pitanja u disciplini zdravstvene skrbi i ima za cilj opisati, predvidjeti i objasniti fenomen njege. Ona sadrži skup ideja, definicija, odnosa, očekivanja i prijedloga koji proizlaze iz modela skrbi ili iz drugih disciplina. Slijedom toga, medicinske sestre moraju cijeniti različite vrste teorija, kritički ih razmatrati i na taj način doprinositi daljnjem razvoju sestrinske znanosti (15). Prema Brownu teorije osiguravaju temelje sestrinske prakse, pomažu u stvaranju daljnjeg znanja i naznačuju smjer u kojem se skrb treba razvijati u budućnosti (16).

\section{PRIRODA SESTRINSKE PRAKSE}

Iako postoji opći konsenzus poimanja sestrinske skrbi potrebno je izvući temeljne značajke u razmatranju njene uloge u praksi. Sestrinska praksa koordinirani je proces koji se sastoji od znanstvenog, tehnološkog, problemu usmjerenog i humanističkog angažmana u pružanju usluga ljudima kojima je to potrebno. Taj proces nastaje u sustavuprovedbe zdravstvene skrbi u kojem medicinske sestre preuzimaju određene vrste odgovornosti (17).

Sestrinska praksa usmjerena je na cilj, što znači da je usmjerena na pomaganjeljudima u problemima i pitanjima koja se odnose na njihovo zdravlje. Ovaj je cilj društveno i pravno određen jer medicinske sestre imaju licencu za praksu u skladu sa zakonom koji određuje što ta praksa mora imati. Medicinske sestre moraju znati mobilizirati vlastite instrumentalne i kulturne resurse (znanje, vještine, tehnike, stavove i vrijednosti) ali i resurse u klijentima i okolišu (18).

U praksi medicinske sestre moraju biti svjesne posljedica svojih postupaka kroz svoje promišljanje, jer promišljanje znači i odabir. Cjelokupno sestrinsko znanje na kraju se svodi na praktični rad. Praksa zahtijeva od medicinske sestre procjenjivanje i promatranje klijenta, provođenja tretmana, brigu, komuniciranje, podučavanje ili savjetovanje. Ishodi sestrinske prakse mjere se u kontekstu očekivanih rezultata određenih tretmana, strategija i intervencija primijenjenih na rješavanje problema klijenata (19).

Rješavanje problema u praksi kompleksan je proces u kojem se problemi moraju kontekstualizirati i tumačiti, a ne samo riješiti ili ukloniti.Prema Nola$n u$, sestrinska se praksa kao ljudska djelatnost mora temeljiti na znanju, a ne samo na intuiciji, osjetljivosti, iskustvu i mudrosti. Oni jesu presudni za sestrinsku praksu, ali trebaju biti povezani sa znanjem (20).

Sestrinska se praksa uopće ne prakticira u izoliranoj ili odvojenoj formi, nego se prakticira zajedno $\mathrm{s}$ drugima sudionicima procesa $\mathrm{u}$ istom vremenskom razdoblju ili povezana u mreži odnosa.Takvi postupci zahtijevaju profesionalan i optimalan rad $\mathrm{u}$ optimalnom vremenu, uz istodobno vrjednovanje čovjeka, njegove osobnosti, vrijednosti i želja, uz poštivanje temeljnih etičkih normi i načela. Upravo zahvaljujući tome, sestrinska praksa je kao takva prepoznata još antičko doba kada ju je Aristotel artikulirao kao čin i djelovanje vođeno moralnom odlukom da se djeluje istinski i pravedno s predanošću ljudskoj dobrobiti $(3,21)$.

\section{PRIMJENA TEORIJE U SESTRINSKOJ PRAKSI}

Prakticiranje sestrinske skrbi temeljeno na znanju u kontekstu sveobuhvatnih obilježja sestrinske prakse i sestrinskih znanja vrlo je složen proces. Budući da se teorije služe općenitim pojmovima u rangiranju pojava i ne bave se pojedinačnim specifičnim pojavama, može se zaključiti da su disciplinska znanja, pa tako i samo sestrinstvo, kao znanstveno utemeljena disciplina, sastavljeni iz više zajedničkih teorija koje razmatraju jedan fenomen. Osim toga, postoje teorije koje se razvijaju u drugim disciplinama a koje imaju doprinos u sestrinskoj praksi, čime znanstveno utemeljena sestrinska klinička praksa 
uključuje zajedničke teorije i načine njihovog prakticiranja u praksi. Dakle, teorije sestrinske prakse općenito se mogu razlikovati kao sestrinske teorije i kao teorije primijenjene za sestrinstvo.

Sama uloga teorije u sestrinskoj kliničkoj praksi može biti dvojaka:

- opća, neodređena uloga koja se koristi za formuliranje orijentacija, stavova i obveza prema temeljnim obilježjima sestrinske prakse koja se prakticira u svim kliničkim situacijama.

- specifična, situacijska uloga koja odgovara zahtjevima specifičnih kliničkih situacija vezanih za sestrinsku praksu (22).

Ove dvije uloge mogu se shvatiti kao dvije razine korištenja teorije u praksi. Sestrinska praksa u određenim kliničkim situacijama uključuje integraciju te dvije teorijske uloge. Brojni autori iz oblasti sestrinstva još od sredine 20. stoljeća bave se određivanja najboljeg modela integracije sestrinskih teorija u praktični rad. To znači da postoji zbirka teorija sestrinstva koje su razvijene kako bi teorijski pristupale pojmovima iz perspektive sestrinstva (23).

Osim toga, postoje teorije koje se razvijaju u drugim disciplinama, a koje imaju doprinos u sestrinskoj praksi, čime znanstveno utemeljena sestrinska klinička praksa uključuje zajedničke teorije i načine njihovog prakticiranja u praksi. Sve one rješavaju ljudske probleme iz perspektive sestrinstva ili predlažu načine pristupa u rješavanju problema zdravlja ljudi. Neke su općenite, dok su druge usko ograničene na specifične kontekste ili situacije. Neke od tih teorija imaju specifično porijeklo skrbi, a druge su rekonstrukcije teorija razvijenih u drugim disciplinama, kao što su biologija, psihologija, sociologija i antropologija. Među tim teorijama postoje intervencijske teorije koje su posebno razvijene za predlaganje terapijskih i skrbničkih pristupa rješavanja zdravstvenih problema ljudi koji su definirani iz perspektive sestrinstva, dok s druge strane imamo i deskriptivne i objašnjavajuće teorije (24).

\section{Opća, nespecifična uloga teorije u sestrinskoj kliničkoj praksi}

$\mathrm{Na}$ općoj razini, okvirno teorijsko znanje mora pružiti osnovu za razumijevanja ljudi i suštine skrbi iz sestrinske perspektive te mora uspostaviti filozofsku obvezu neophodnu za praksu sestrinstva. Stoga su teorijski ili konceptualni okviri sestrinstva orijentirani na određivanje osnovnih obilježja ljudi i ljudskih potreba, na način najprikladniji za prvu razinu u uspostavljanju sestrinske prakse. Uloga koju igraju teorijski okviri sastoji se u usmjeravanju medicinske sestre na razumijevanje ljudi i njihovih problema te na odnos prema skrbi i njenoj praksi na specifičan način sukladan disciplini iz kojih su proizašli (25).

Opće okvirne teorije i teorije o potrebama igraju veliku ulogu u određivanju sestrinske perspektive. Sestrinstvo još uvijek traži jedinstvenu teoriju o sestrinskom poimanju prakse koja će zadovoljiti sve standarde. Na primjer, pokušaj od strane NANDA (North American Nursing Diagnosis Association) osamdesetih godina prošlog stoljeća za uspostavljanjem jedinstvene okvirne teorije sestrinske skrbi, na način da poveže mnoge velike teorije skrbi u jednu teoriju nije rezultirao usvajanjem (26).

Drugu komponentu opće razine teorije sestrinske prakse tvori okvirno znanje iz filozofije, koje obuhvaća filozofiju skrbi, terapije i profesionalnog rada te određuje normativne elemente koji detaljno oblikuju kliničku praksu sestrinstva. Teorije koje naglašavaju filozofska obilježja skrbničke prakse temelj su kojim medicinske sestre uspostavljaju svoje stavove prema skrbi, terapiji i profesionalnom radu, čime se ove filozofske obveze potvrđuju u kliničkoj praksi. Još uvijek ne postoje teorije koje se bave filozofijom terapije i filozofijom profesionalnog rada, posebno gledano iz perspektive sestrinstva. Još uvijek postoji potreba za razvijanjem takvih teorija čime bi se uspostavila kvalitetnija teorijska osnova za sestrinsku praksu $(22,27)$.

\section{Specifična uloga teorije u sestrinskoj kliničkoj praksi}

Teorije se mogu selektivno primjenjivati u rješavanju problema u specifičnim kliničkim situacijama u sestrinskoj praksi. Na ovaj način moguće je konceptualizirati kliničku sestrinsku skrb u različitim oblicima. Primjerice, ovakva uloga teorije dopušta široko definiranje potreba bolesnika koji je hospitaliziran s dijagnozom moždanog udara, ali dopušta 
i mnogo uže definiranje potreba, kao što je primjerice pojava boli u bolesnika u poslijeoperacijskom razdoblju. Na ovoj razini uloga teorije specifična je u ovisnosti od kliničke situacije. Pretpostavka je da su karakteristike sestrinske prakse u takvim situacijama određene prvenstveno ulogom prve razine sestrinske teorije, pružajući općenitije načine provedbe prakse, ali ujedno i specifične, koristeći primijenjene teorije sestrinstva na drugoj razini (28).

Uloga teorije na drugoj razini odnosi se na strukture dimenzije (znanstvene, tehničke, etičke i estetske) i strukture procesa (promišljanja i donošenja). Opće znanje i teorija osnova su određivanja specifičnih sestrinskih postupaka koje pokazuju znanstvena, tehnička, etička i estetskaobilježja. Teorije na ovoj razini temelj su osnove kliničke prakse koja se prerađuje kroz promišljanje i donošenje, a zastupljene su u svačetiri navedena dimenzijska obilježja koja su integrirana zajedno $(7,8)$.

\section{Uloga teorije u znanstvenoj dimenziji sestrinske kliničke prakse}

Znanstvena dimenzija sestrinskih postupaka u praksi predstavlja izbor i primjenu onih teorija koje pružaju odgovore na klinička pitanja u određenoj situaciji. Ova se dimenzija oslanja na znanstvenu racionalnost, koja se temelji na principima logike i iskustva u primjeni znanstvenih teorija u sestrinskoj kliničkoj praksi. Postoje mnoge znanstvene teorije koje su se razvijale kako bi se odgovorilo na klinička pitanja. Neke od njih su široke, opće teorije, dok su druge teorije specifične za određene situacije. Neke su orijentirane na pružanje razumijevanja i objašnjenja, dok su druge usmjerene na rješavanje kliničkih problema. S obzirom na to da određena klinička situacija, premda usko definirana, obuhvaća višestruke pojave koje se moraju promatrati kao međusobno povezane, uloga je teorije na toj razini u dobivanju sveobuhvatnih odgovora na što je moguće više kliničkih pitanja $(17,22)$.

\section{Uloga teorije u tehničkoj dimenziji sestrinske kliničke prakse}

Tehnička dimenzija sestrinskih postupaka predstavljena je općim načelima racionalnosti. Opća načela tehničke racionalnosti koja se primjenjuju u sestrinskoj kliničkoj praksi su optimalnost, koordinacija, povezanost i fleksibilnost. Tehnička racionalnost temeljena na tim načelima omogućava učinkovitu izvedbu sestrinske kliničke prakse u rješavanje problema klijenata i njihovih potreba. Uloga teorije kod ove tehničke dimenzije sestrinske kliničke prakse sastoji se u davanju smjernica za provedbu navedenih načela. Teorija koje igraju glavnu ulogu potrebnu za oblikovanje tehnika sestrinske prakse uglavnom su primijenjene teorije (19).

\section{Uloga teorije u etičkoj dimenziji sestrinske kliničke prakse}

Etička dimenzija sestrinskih postupaka regulirana je moralnom razumnošću u kojoj se vrše izbori i postupci u provedbi sestrinske prakse. Opća moralna načela primijenjena u sestrinskoj praksi su holističko razumijevanje, istinitost, dosljednost i suosjećanje. Uloga teorije u toj dimenziju sastoji se u pružanju normativne osnove u obvezi pružanja sestrinske skrbi klijentima (29).

\section{Uloga teorije u estetskoj dimenziji sestrinske kliničke prakse}

Estetska dimenzija sestrinske prakse regulirana je estetskom racionalnošću proisteklom iz značajki utemeljenih u praksi. Opća načela estetske dimenzije koja se primjenjuju u sestrinskoj kliničkoj praksi su harmonija, prikladnost i finoća (finesa). Da bi sestrinski postupci dobili estetsku dimenziju potrebno je primijeniti znanje o kreativnosti i dizajnu u praksi sestrinstva. Uloga teorije u provedbi te dimenzije sastoji se u davanju smjernica sestrinskom djelovanju koje mora biti individualističko, kreativno i sukladno svakoj mogućoj kliničkoj situaciji $(30,31)$.

\section{ZAKLJUČAK}

Sestrinska klinička praksa zasniva se na teorijama koje se temeljena općim i partikularnim razinama. To znači da na općoj razini sestrinska praksa mora biti holistički konfigurirana općim teorijama koje određuju sadržaje i sestrinske stavoveu filozofiji skrbi, terapiji i profesionalnom radu. 
$\mathrm{Na}$ temeljnoj razini sestrinske prakse teorije igraju glavnu ulogu u uspostavi orijentacija i obveza. Istodobno, sestrinska praksa oblikovana je specifičnim teorijama potrebnim za rješavanje pitanja u svim mogućim kliničkim situacijama. Sestrinsku praksu karakteriziraju teorije koje se primjenjuju u ispunjavanju znanstvenih, tehničkih, etičkih, estetskih dimenzija i teorije koje se primjenjuju u procesima rješavanja kliničkih pitanja.

Medicinske sestre u svojoj praksi moraju sintetizirati više vrsta teorija kako bi osigurale najbolji mogući klinički odgovor te ujedno dizajnirati i specifične pristupe u praksi, kako bi odgovorile na zahtjeve specifičnih kliničkih situacija i pružile skrb koja pokazuje najbolje moguće značajke u znanstvenim, tehničkim, etičkim i estetskim dimenzijama.

\section{LITERATURA}

1. Hickman JS. An introduction to nursing theory. Nurs Sci Q. 2013;1:15-22.

2. Geary CR, Schumacher KL. Integrating transition theory and complexity science concepts. Adv Nurs Sci. 2012;35:236-48.

3. Matulić T. Identitet, profesija i etika sestrinstva. Ephemerides theologicae Zagrabienses. 2007;77:727-44.

4. Colley S. Nursing theory: its importance to practice. Nurs Stand. 2010;17:33-7.

5. Daly J, Mitchell GJ, Toikkanen T, Millar B, Zanotti R, Takahashi T, i sur. What is nursing science? An international dialogue. Nur Sci Q. 1997;8:10-3.

6. Barrett EAM. Again, what is nursing science?Nurs Sci Q. 2016;30:129-33.

7. Kim HS. The role of theory in clinical nursing practice. Clin Nurs. 2012;2:16-28.

8. Shea L, Frisch NC. Application of integral theory in holistic nursing practice. Nurs Sci Q. 2014;28:344-52.

9. Mojsović Z. Sestrinstvo u zajednici. Zagreb: Zdravstveno veleučilište Zagreb; 2006.

10. James KM. Incorporating complexity science into nursing curricula. Creat Nurs. 2011;16:137-42.
11. Fiandt K, Forman J, Megel ME, Pakieser RA, Burge $S$. integral nursing: an emerging framework for engaging the evolution of the profession. Nurs Outlook. 2013;51:130-7.

12. Wieck KL. A vision for nursing: The future revisited. Nursing Outlook. 2012;48:7-18.

13. Castledine G. The role of the nurse in the $21 \mathrm{st}$ century. Br J Nurs. 1994;3:621-2.

14. Rogers ME. Nursing science and the space age. Nurs Sci Q. 2008;5:27-34.

15. Jarrin O. An integral philosophy and definition of nursing. J Integr Theory Pract. 2011;2:79-101.

16. Brown M. Research in the development of nursing theory: the importance of a theoretical framework in nursing research. Nurs Resear. 1999;13:109-12.

17. Dossey BM. Theory of integral nursing. Adv in Nurs Sci. 2008;3:52-73.

18. Rose P, Parker D. Nursing: an integration of art and science within the experience of the practitioner. J Adv Nurs. 2004;20:1004-10.

19. Hardy M. Perspectives on nursing theory. Adv Nurs Sci. 2012;1:27-48.

20. Nolan M. Nursing's knowledge base: does it have to be unique? BJ Nurs. 2008;7:270-6.

21. Miller A. The relationship between nursing theory and nursing practice. J Adv Nurs. 2005;10:417-24.

22. Kim HS. Practice theories in nursing and a science of nursing practice. Sch Inq Nurs Pract. 1994;8:145-58.

23. Kenny T. Nursing models fail in practice. B J Nurs. 2000;2:133-5.

24. Reed PG, Rolfe G. Nursing knowledge and nurses' knowledge: A reply to Mitchell and Bournes. Nurs Sci Q. 2006;19:120-3.

25. Hardy M. Perspectives on nursing theory. Adv Nurs Sci. 2001;1, 1, 27-48.

26. George J. Nursing theories: The base for professional practice, 6th ed. Upper Saddle River, NJ: Prentice Hall; 2011.

27. Parse RR. The discipline and the profession. Nurs Sci Q. 2009;12:275-81. 
28. Gavranić G, Iveta V, Sindik J. Konceptualni modeli sestrinstva i načela sestrinske prakse. Nurs J. 2016;21:148-52.

29. Liaschenko J. Ethics in the work of acting for clients. Adv Nurs Sci. 2005;18:1-12.
30. Gadow S. Relational narrative: The postmodern turn in nursing esthetics. Sch Inq Nurs Pract. 1999;13:57-70.

31. Rogers ME. The science of unitary human beings. Nurs Sci Q. 2004;7:33-5. 


\title{
NURSING THEORIES AND THEIR APPLICATION IN NURSING CLINICAL PRACTICE
}

\author{
Boris Kovač \\ Faculty of Health Studies, University of Mostar, Bijeli Brijeg b.b., Bosnia and Herzegovina
}

\begin{abstract}
Nursing theory is a prudent systematic term of recommendations related to issues in the healthcare discipline. It represents a set of ideas, definitions, relations, expectations, and propositions that arise from care models or other disciplines forming specific interrelations between concepts, for the purpose of describing, explaining, predicting, and recommendations. The role of nursing science theory is of great importance in the process of implementation of acquired knowledge in nursing clinical practice. Nursing practice theories led to the identification of an authentic nursing identity and together with the development of technology and humanities shaped the authentic nursing practice. The theories are used in clinical practice in two different manners. The first is a general, orientation role of the theory used to formulate the attitudes and obligations according to fundamental characteristics of the nursing practice and by this influence the implementation of care in all clinical situations. The second manner is a selective and situational role that corresponds to specific demands in clinical practice. In this way, the nursing practice ultimately becomes knowledge which is based on the integration of these two manners of application of nursing theory. Objective: Test nursing theories and ways of their application in nursing clinical practice.
\end{abstract}

Key words: theory, nursing, application, clinical practice

Correspondence:

Boris Kovač

E-mail: boris.v.kovac@gmail.com 